\title{
INFLUENCE OF THE INCORRECT SETTINGS OF AXIAL COMPRESSOR INLET VARIABLE STATOR VANES ON GAS TURBINE ENGINE WORK PARAMETERS
}

\author{
Pawel Wirkowski \\ Polish Naval Academy \\ Department of Mechanical and Electrical Engineering \\ Smidowicza Street 69, 81-103 Gdynia, Poland \\ tel.: +4858 6262756, fax: +48586262963 \\ e-mail:p.wirkowski@amw.gdynia.pl
}

\begin{abstract}
The paper deals with the problem of influence of changes variable stator vanes axial compressor settings of gas turbine engine on work parameters of compressor and engine. Incorrect operation of change setting system of variable vanes could make unstable work of compressor and engine. This paper presents theoretical analysis of situation described above and results of own research done on real engine.

When in the compressor construction there is assembled system of setting change of variable stator vanes its task is to make optimal cooperation engine units during the permanent improvement of compressor characteristic. Perturbations in the operation of this system could cause changes in work of compressor and engine similarly as in the case of changes caused by changes of rotational speed or polluted interblades ducts of compressor.

The purpose of investigations, which was carried out on real engine was determination influence of incorrect operation of axial compressor inlet guide variable stator vanes control system of gas turbine engine on compressor and engine work parameters. The object of research is type DR 77 marine gas turbine engine, which is a part of power transmission system of war ship. In compressor construction configuration of this engine there are used inlet guide stator vanes which make possibilities to change the setting angle incidance (change of compressor flow duct geometry) in depend on engine load. On the base of results of experiment there were determined the mathematical equations modelling the changes of particular engine work parameters in the function of variable inlet guide stator vanes setting angle.
\end{abstract}

Keywords: gas turbine, axial compressor, variable stator vanes

\section{Introduction}

When in the compressor construction is assembled system of setting change of variable stator vanes its task is to make optimal cooperation engine units during the permanent improvement of compressor characteristic. Perturbations in the operation of this system could cause changes in work of compressor and engine similarly as in the case of changes caused by changes of rotational speed or polluted interblades ducts of compressor.

Compressor stage unitary work on radius is defined on the base of equation of angular momentum and it has form"

$$
l_{s t}=\omega \cdot r \cdot\left(c_{2 u}-c_{1 u}\right)=u \cdot \Delta c_{u}=u \cdot \Delta w_{u},
$$

where:

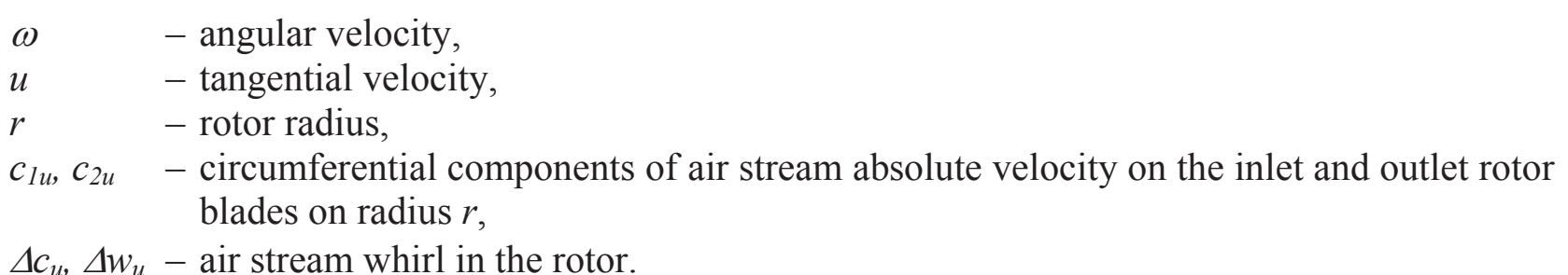


That work is constant on whole depth of rotor blade. The sum of works is the unitary work of stage. Involved change of variable stator vanes angle setting at a constant level rotational velocity (constant $u$ ) caused change of air stream inlet angle in rotor vane $\beta_{l}$ (Fig. 1). It caused change of axial component of air stream absolute velocity on inlet $c_{1 a}$ what is equivalent with the change of air mass flow $\dot{m}$ and change of air stream whirl $\Delta w_{u}$ in rotor. It influences on efficiency and work of stage.

The purpose of investigations, which was carried out on real engine was determination of influence of incorrect operation of axial compressor inlet guide variable stator vanes control system of gas turbine engine on compressor and engine work parameters.

Compressor characteristic is a relationship between compression ratio $\pi_{C}^{*}$, compressor efficiency $\eta_{C}^{*}$ and air flow mass $\dot{m}$ and compressor rotational velocity $n$. It makes possible to determine the best condition of compressor and another engine units mating. The characteristic is used to select optimal conditions of air flow regulation and assessment of operational factors on compressor parameters.

Therefore compressor should be so controlled in operational range of rotational velocity that the compressor and engine mating line has a stock of stable work. The main rule of compressor control during the change of their rotational velocity or flow intensity is to keep up the stream inlet angles $i$ value near zero. One of the most popular ways of axial compressor control is changing their flow duct geometry by application of inlet guide stator vanes or variable stator vanes of several first compressor stages.

This solution makes it possible to change of air stream inlet angle on rotor blades of compressor stages by change of stator vanes setting angles during the change of compressor rotational velocity. Fig. 1 illustrates the rule of regulation of variable stator vanes.

For average values of operational range of compressor rotor speed is situation in Fig. $1 \mathrm{~b}$ - speed values and directions with subscript number 1 . In this situation is intermediate angle setting of stator vanes. Air stream inlet angle on rotor blades do not cause disturbance of stream flow by interblades ducts. For lower values of compressor rotor speed and in consequence lower values of absolute axial component velocity $c_{1 a}$, it is necessary to reduce the stream outlet angle of variable stator vanes $\alpha_{1}$ (Fig. 1a). The angle reduction range should allow keeping the same value of stream inlet angle on rotor blades. Analogical situation takes place during the work of compressor with higher rotational speed. For higher rotational speed absolute axial component speed $c_{l a}$ increases. In this situation for keeping stable work of compressor and in consequence constant value of stream inlet angle on rotor blades, it is necessary to increase the stream outlet angle of variable stator vanes - Fig. 1c. Application in gas turbine engine construction of control system of flow ducts geometry has a bearing on a run of unstable processes.

\section{Object of research}

The object of research is type DR 77 marine gas turbine engine (Fig. 2), which is a part of power transmission system of a warship. It is three-shaft engine with can-ring-type combustor chamber and reversible power turbine.

In compressor construction configuration of this engine there are used inlet guide stator vanes which make possibilities to change the setting angle incidance (change of compressor flow duct geometry) in dependance on engine load. This process is operated by control system which working medium is compressed air received from last stage of high pressure compressor. On Fig. 3 is presented block diagram of flow control signal of variable stator vanes system.

Compressed air from the last stage of high pressure compressor is supplied to working space of control actuator by cleaning and cooling block. Compressed air exerts pressure on control actuator elements. It causes moving of control piston which is connected with moving ring. This ring moves on circumference of compressor body. Ring is connected with stator vanes by levers. When the ring is moving stator vanes realize rotational motion changing the air stream outlet angle $\alpha_{1}$ (Fig. 1). In cleaning and cooling block are made holes. During research air stream was bleeded by the holes and less air was supplied to the actuator. It caused change of setting angle $\alpha_{V I G V}$ of variable stator vanes. In consequence of that change flow duct geometry was changed. 


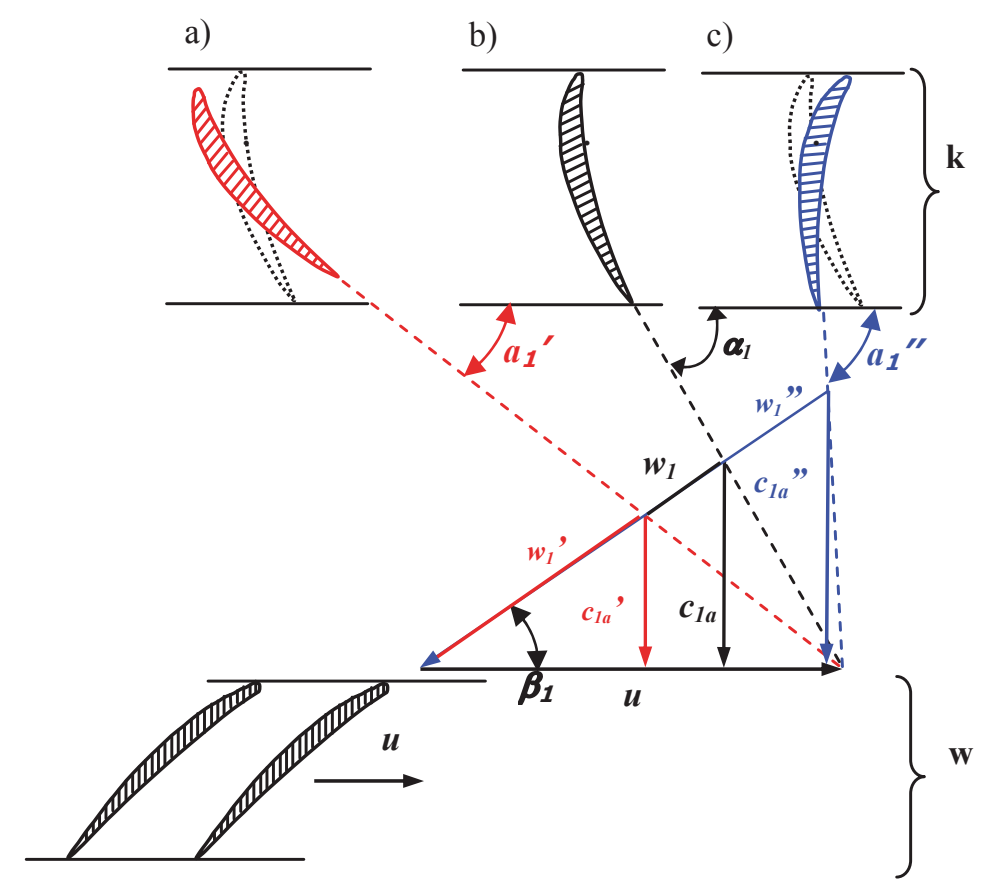

d)
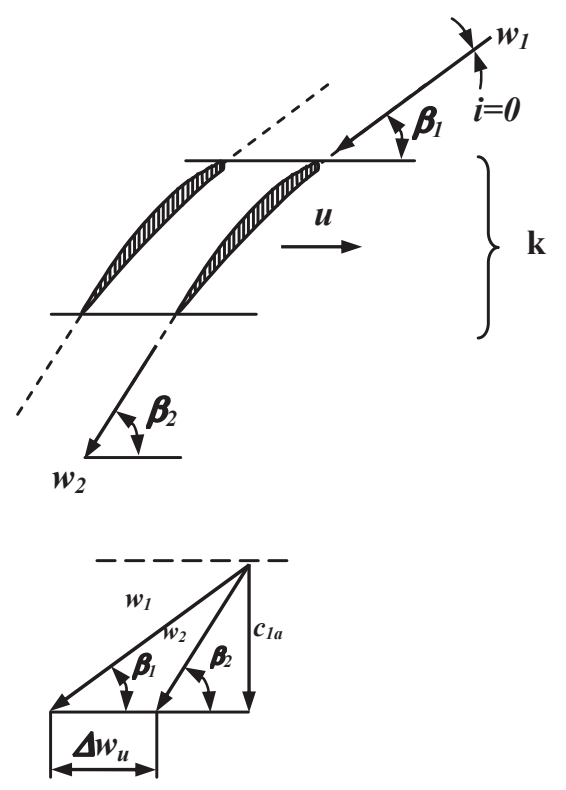

Fig. 1. Essence of control of compressor's axial stage by changing the setting angle of stator vanes ring at changeable air flow velocity; a) decreased axial velocity, b) analytical axial velocity, c) increased axial velocity, d) schema of flow round of axial compressor rotor blades during constant rotor speed and constant air stream inlet angles; $k$-variable stator vanes ring, $w$-rotor vanes ring

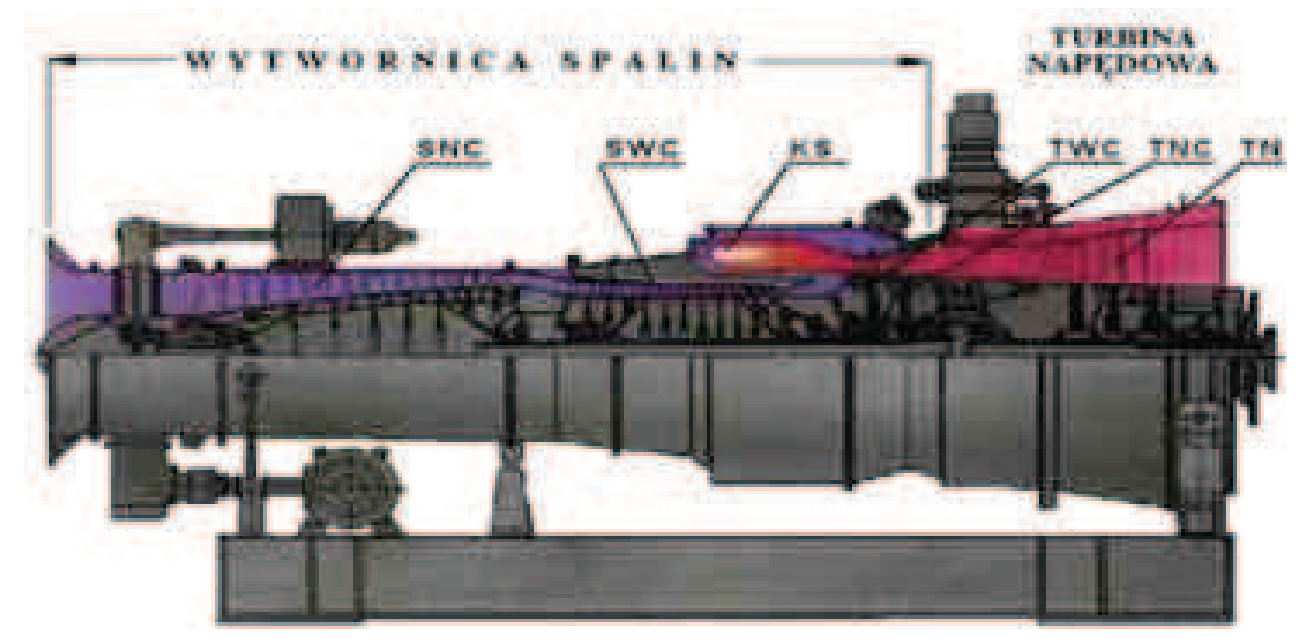

Fig. 2. Type DR 77 marine gas turbine engine

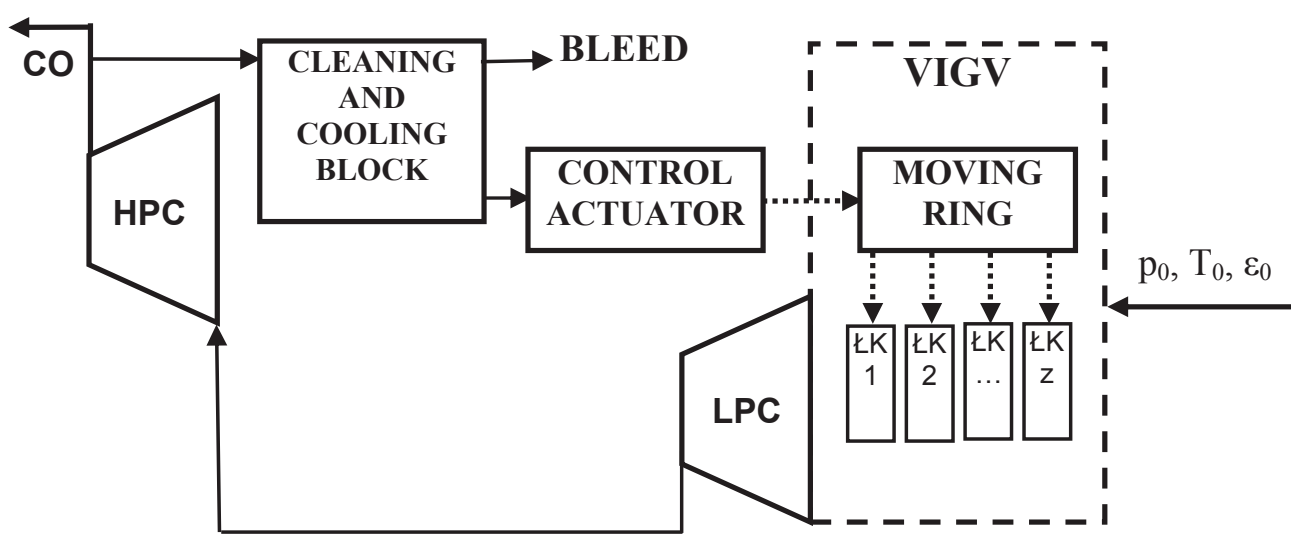

Fig. 3. Block diagram of stator vanes change setting mechanism 
The experiment was carried out on an engine load $0,5 \mathrm{P}_{\text {nom }}$ with taking into consideration atmospheric conditions. For this load setting angle of variable vanes has value $\alpha_{V I G V}=-4^{\circ}$. During change engine load in the whole range from idle to full load setting angle $\alpha_{V I G V}$ of variable vanes changes in range from $-18^{\circ}$ to $+18^{\circ}$. During experiment a few parameters of engine work was measured and registered. It was made for three different setting angle $\alpha_{V I G V}$ of variable vanes: A$\alpha_{V I G V}=-4^{\circ}, \mathrm{B}-\alpha_{V I G V}=-11^{\circ}, \mathrm{C}-\alpha_{V I G V}=-18^{\circ}$. Tab. 1 presents measured and registered parameters.

Tab. 1. Parameters of engine DR77 work measured during research

\begin{tabular}{|c|c|c|l|}
\hline Parameter & Measurement range & Unit & \multicolumn{1}{|c|}{ Parameter name } \\
\hline $\mathrm{n}_{\mathrm{LPC}}$ & $0-20000$ & {$[\mathrm{rpm}]$} & low pressure rotor speed \\
\hline $\mathrm{n}_{\mathrm{HPC}}$ & $0-22000$ & {$[\mathrm{rpm}]$} & high pressure rotor speed \\
\hline $\mathrm{n}_{\mathrm{PT}}$ & $0-10000$ & {$[\mathrm{rpm}]$} & power turbine rotor speed \\
\hline $\mathrm{p}_{1}$ & $-0.04-0$ & {$[\mathrm{MPa}]$} & subatmospheric pressure on compressor inlet \\
\hline $\mathrm{p}_{21}$ & $0-0.6$ & {$[\mathrm{MPa}]$} & air pressure on low pressure compressor outlet \\
\hline $\mathrm{p}_{2}$ & $0-1.6$ & {$[\mathrm{MPa}]$} & air pressure on high pressure compressor outlet \\
\hline $\mathrm{p}_{\mathrm{p}}$ & $0-10.0$ & {$[\mathrm{MPa}]$} & fuel pressure before injectors \\
\hline $\mathrm{T}_{1}$ & $-203-453$ & {$[\mathrm{~K}]$} & air temperature on compressor inlet \\
\hline $\mathrm{T}_{42}$ & $273-1273$ & {$[\mathrm{~K}]$} & exhaust gases temperature on inlet power turbine \\
\hline
\end{tabular}

\section{Results of research}

Change angle vanes setting from position $A$ to position $C$ caused the increase of air flow resistance by stator vanes. In consequence of that subatmospheric pressure on the compressor inlet $p_{l}$ decreases. It causes pressure decrease in next parts of compressor and engine flow duct. In this way reduced air density flowing by compressor, for stable quantity of stream fule supllied to combustor, causes increase of compressors rotor speed. The most noticeable is increase of low pressure compressor rotor speed caused by directly influence on this compressor incorrectly setting variable stator vanes. Gasodynamical connection between the low pressure compressor and the high pressure compressor absorbs disturbances work of low pressure compressor which are transferred on high pressure compressor. Therefore range of change high pressure compressor rotor speed is lower than low pressure compressor. In this experiment it is below $1 \%$ and it is in measuring error of sensor range.

Change of subatmospheric pressure is above $5 \%$ undisturbed value of this parameter. Changes of low and high pressure compressor outlet presure are adequately above $1.3 \%$ and above $2.4 \%$ undisturbed value of angle setting $\alpha_{V I G V}=-4^{\circ}$.

Changes of pressure and air mass flow intensity values accompanied disturbed work of compressor, during constant fuel mass flow intensity in combustor, caused enrichment of fuel mixture. As a result of that, temperature combustor outlet gases increases. In experiment was confirmed the tendency changes of gases tempertaure values even though the range of those changes is in measuring error of sensor range.

On the base of results of experiment there were determined the mathematical equations modelling the changes of particular engine work parameters in the function of variable inlet guide stator vanes setting angle $\alpha_{V I G V}$ :

$$
\begin{gathered}
n_{L P C}=0.7449 \cdot \alpha_{V I G V}{ }^{2}+2.602 \cdot \alpha_{V I G V}+9234.5, \\
n_{H P C}=0.0204 \cdot \alpha_{V I G V}{ }^{2}-1.1224 \cdot \alpha_{V I G V}+12598, \\
p_{1}=-10^{-6} \cdot \alpha_{V I G V}{ }^{2}-10^{-6} \cdot \alpha_{V I G V}+0.0077, \\
p_{2.1}=10^{-16} \cdot \alpha_{V I G V}{ }^{2}+0.0029 \cdot \alpha_{V I G V}+2.9814, \\
p_{2}=2 \cdot 10^{-16} \cdot \alpha_{V I G V}{ }^{2}+0.0143 \cdot \alpha_{V I G V}+8.1771, \\
T_{42}=0.020 \cdot \alpha_{V I G V}{ }^{2}+0.1633 \cdot \alpha_{V I G V}+526.33 .
\end{gathered}
$$


Figure 4 presents results of mathematical modelling of engine work parameters. Modelling was cary out an state engine load what was equivalent unchangable fuel mass flow. In this case range of change of variable inlet guide stator vanes angle setting $\alpha_{V I G V}$ was widen from $-18^{\circ}$ to $+18^{\circ}$. Research in range $\alpha_{V I G V}$ from $-4^{\circ}$ to $+18^{\circ}$ were not possilble to realize on real engine. It is caused by technical restrictions on the engine.
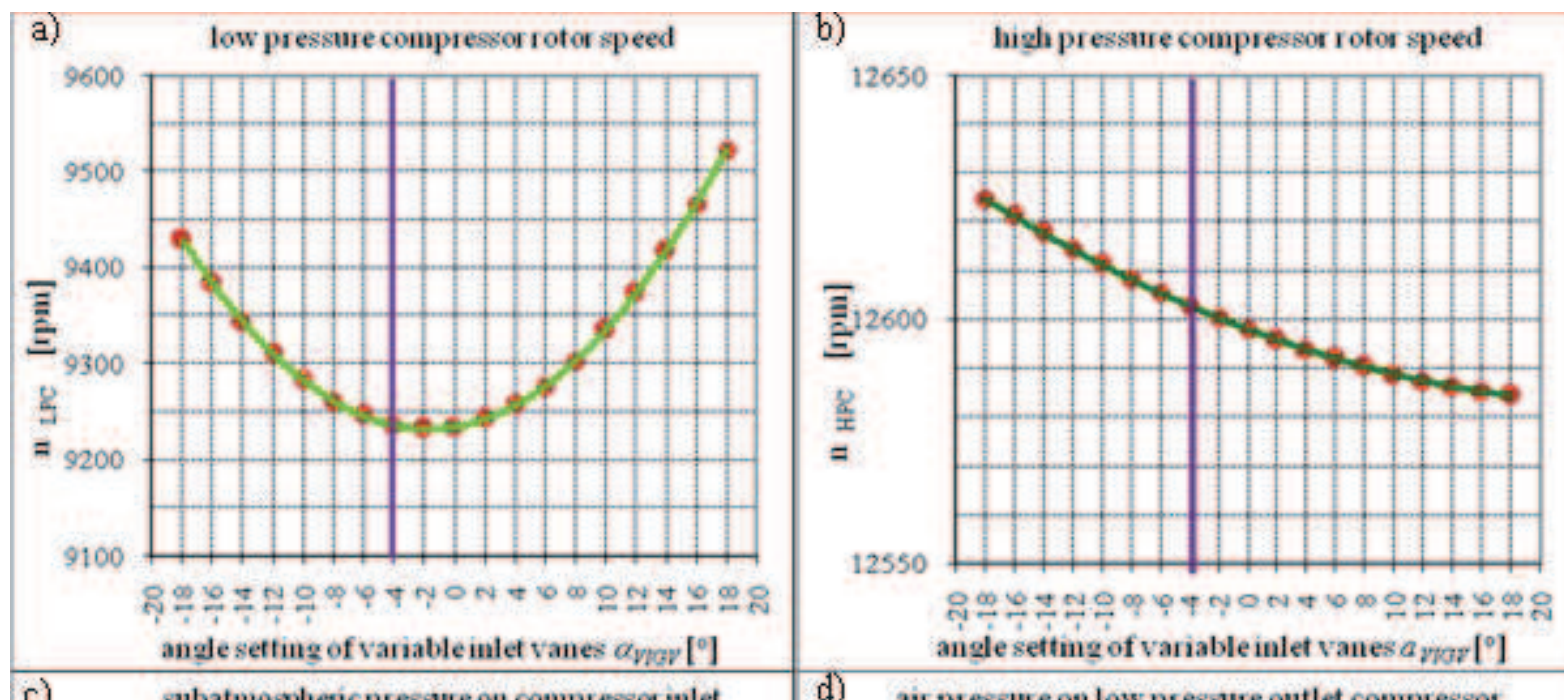

c) subatmosphenicpressure on compresser inlet
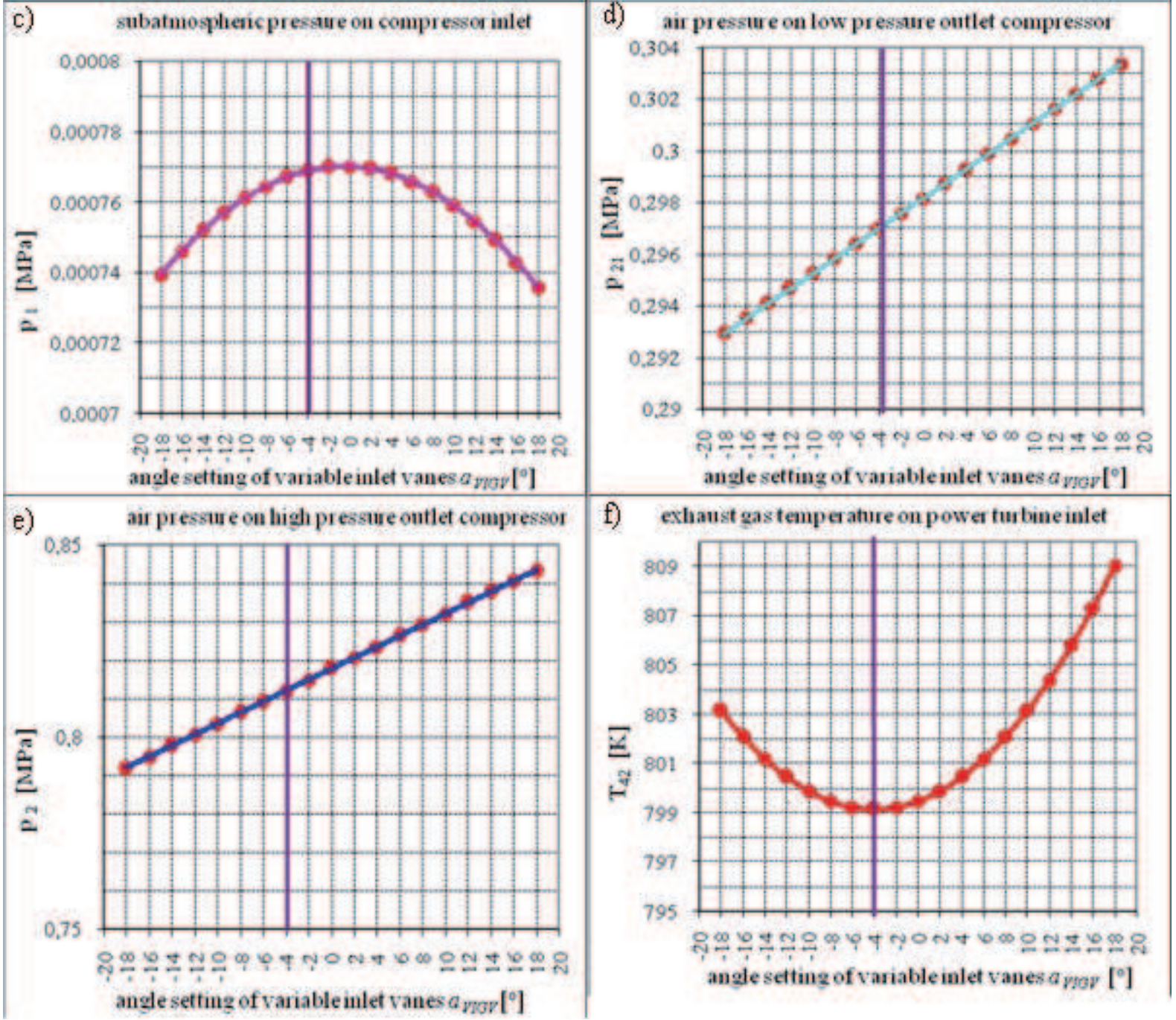

Fig. 4. Change of values of engine work parameters in function of variable inlet guide stator vanes setting angle gotten during mathematical simulation 
Figure 5 presents results of mathematical modelling of engine work parameters in relative values. Parameters obtained during the tests have been referenced to the values in the undistorted work of engine. This work is characterized by $50 \%$ nominal engine load and variable inlet guide vanes angle setting $\alpha_{V I G V}=-4^{\circ}$.

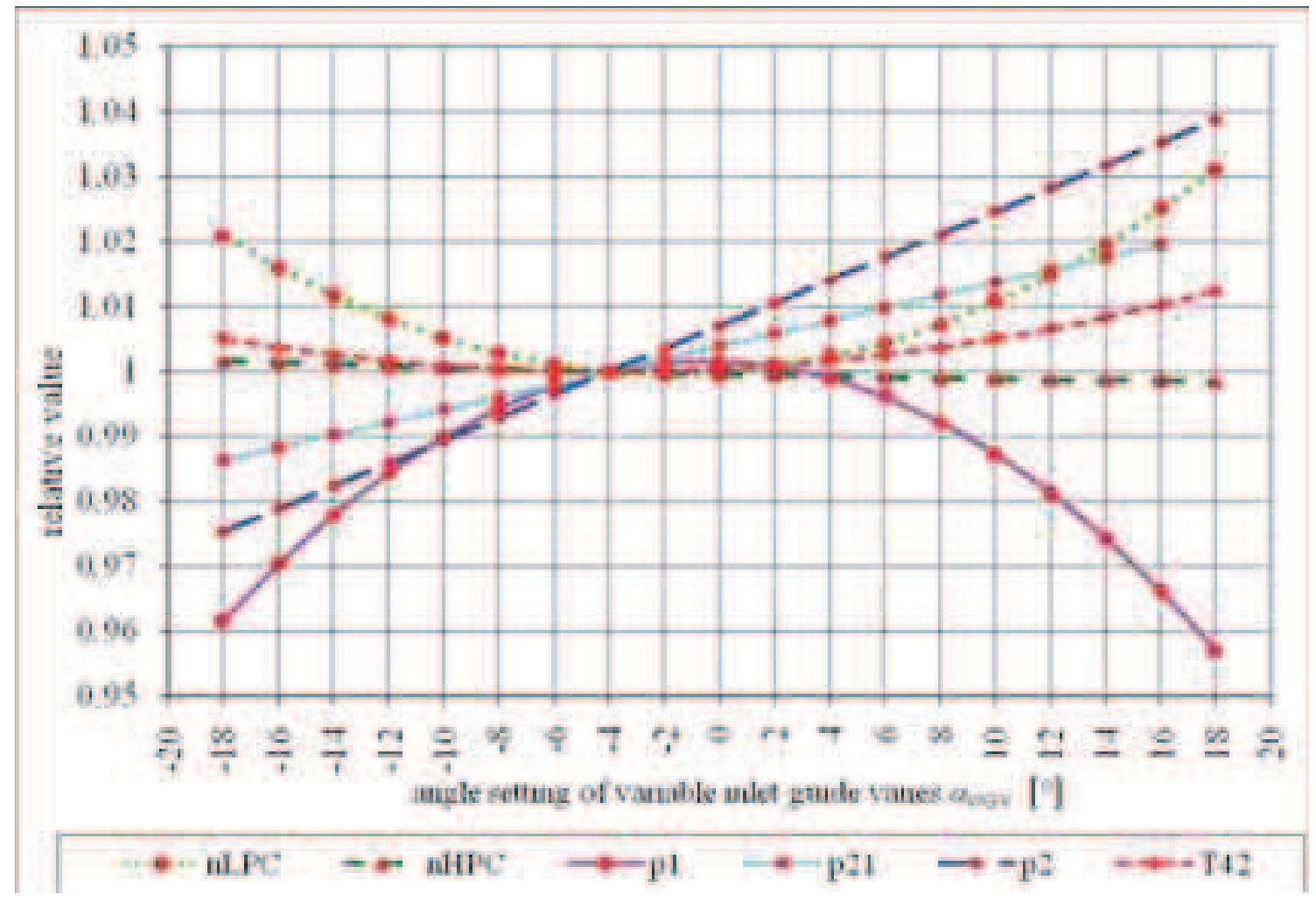

Fig. 5. Results of mathematical modeling of engine work parameters in relative values

\section{Conclusions}

Change of values of variable inlet guide stator vanes setting angle $\alpha_{V I G V}$ from $-4^{\circ}$ to $+18^{\circ}$ caused the increase of stream outlet angle of variable stator guide vanes $\alpha_{1}$ (Fig. 1). It decreases air flow drag on low pressure compressor inlet that caused decrease of subatmospheric pressure. During keeping the constant engine load (constant fuel mass flow) absolute axial component velocity $c_{1 a}$ increases. It exerts an influence on air mass flow $\dot{m}$ increase. Simultaneously the absolute axial component velocity $c_{l a}$ increase caused decrease of air stream whirl in rotor $\Delta w_{u}$. In consequence of that low pressure compressor rotor speed increases (Fig. 4a). In connection with decrease of subatmospheric pressure the increase of air pressure on low pressure outlet compressor is caused (Fig. 4d). In spite of the slight decrease of high pressure compressor rotor speed the increase of air pressure on low pressure outlet compressor involves the increases of air pressure on high pressure outlet compressor (Fig. 4e). This slight decrease of high pressure compressor rotor speed caused increase of gases flow drag in the next gas turbine engine units for the combustor. The effect of above is a slight increase of exhaust gas temperature on power turbine inlet.

Multi-shaft construction of gas turbine engine reduces effects of incorrectly setting of variable vanes. Therefore compressors of three-shaft gas turbine engine do not require variable stators vanes as many stages as compressor of two-shaft engine with the same achievements.

Preliminary research confirms the necessity of inspection the correct operation of variable stator vanes system control. It makes possibility of elimination this factor from group of factors informing about technical state of engine, which are identified during the diagnostic inspections. 


\section{References}

[1] Charchalis, A., Diagnostics of marine gas turbine engines (in Polish), Published by Polish Naval Academy, Gdynia 1991.

[2] Dżygadło, Z. et al., Rotor units of gas turbine engines (in Polish), Transport and Telecommunication Publishing House (WKiŁ), Warszawa 1982.

[3] Korczewski, Z., Wirkowski, P., Modelling gasodynamic processes within turbine engines' compressors equipped with variable geometry of flow duct, IV International ScientificallyTechnical Conference Explo-Diesel \& Gas Turbine, Wydawnictwo Politechniki Gdańskiej, pp. 227-236, Gdańsk 2005.

[4] Marschal, D. J., Muir, D. E., Saravanamuttoo, H. I. H., Health Monitoring of Variable Geometry Gas Turbines for the Canadian Navy, The American Society of Mechanical Engineers 345 E, 47 St., New York, N.Y.10017.

[5] Wirkowski, P., Modelling the characteristics of axial compressor of variable flow passage geometry, working in the gas turbine engine system, Polish Maritime Research, No 3/2007, Published by Gdańsk University of Technology, pp. 27-32, Gdańsk 2007.

[6] Wirkowski, P., Simulation of changes of gas turbine engine work parameters equipped with variable inlet stator vanes axial compressor, $12^{\mathrm{TH}}$ International Conference Computer systems aided science, industry and transport, TRANSCOMP, Published by Radom University of Technology, 591-596, Radom 2008.

[7] Wirkowski, P., Influence of axial compressor flow passage geometry changes on gas turbine engine work parameters, VI International Scientifically-Technical Conference POLISH CIMAC Explo-Diesel \& Gas Turbine '09, Published by Gdańsk University of Technology, Vol.2, Gdańsk 2009.

\section{Parameters, abbreviations and subscripts}

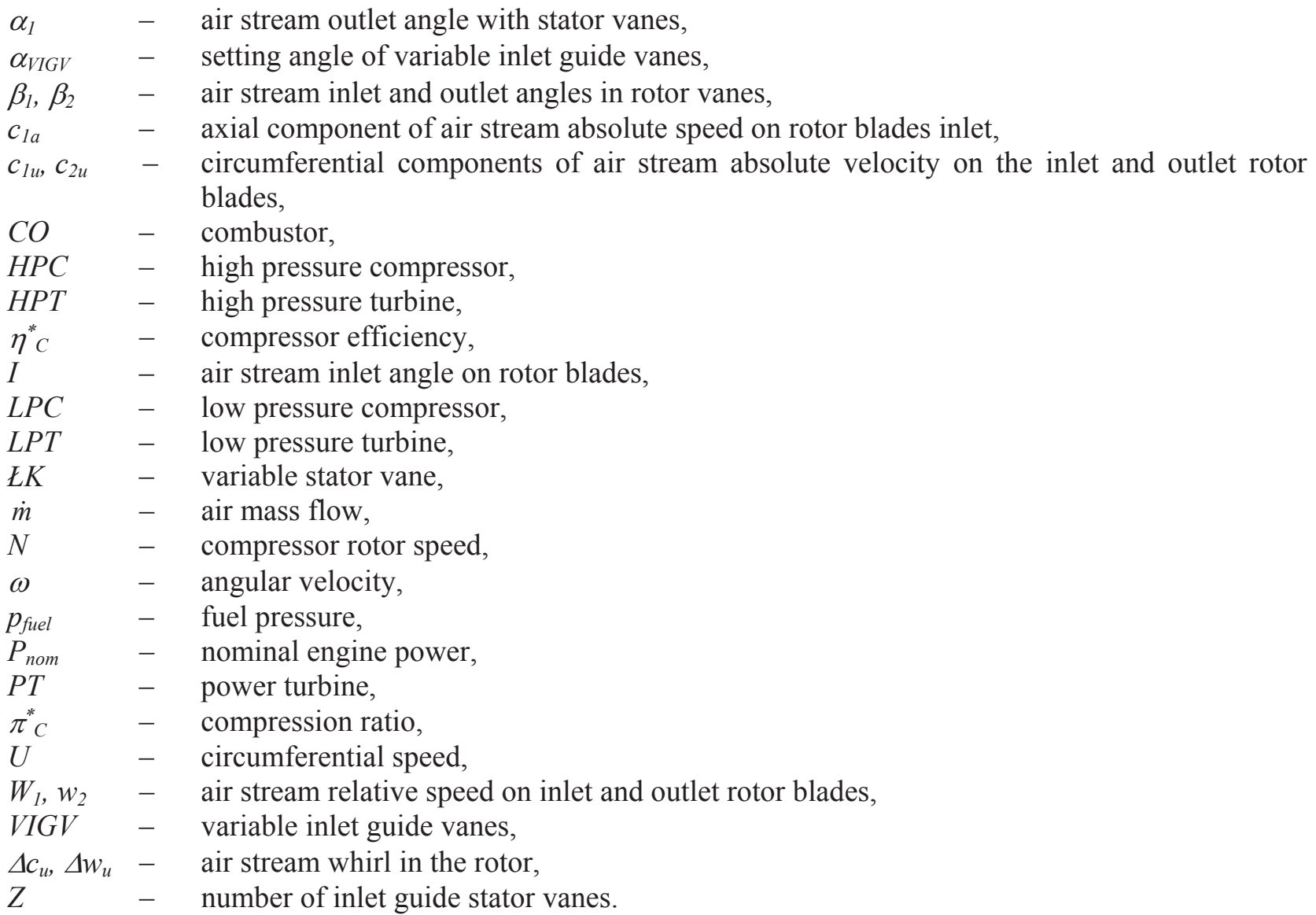

